\title{
Perhitungan Tingkat Pemerataan Layanan Internet
}

\author{
Sigit Haryadi \\ Institut Teknologi Bandung \\ March 2018
}

Paper DOI10.17605/OSF.1O/RGCT3

Sitasi: Haryadi, S. (2018, March 6). Perhitungan Tingkat Pemerataan Layanan Internet. Retrieved from osf.io/preprints/inarxiv/rgct3

\begin{abstract}
Abstrak
Metode menghitung pemerataan layanan internet di suatu wilayah atau negara merupakan suatu ukuran statistik yang menunjukkan sejauh mana distribusi kecepatan layanan internet dari beberapa kota di suatu wilayah atau negara yang sedang diukur adalah memiliki kemiripan dengan distribusi rujukan yang semua unsurnya sama dengan satu, dimana penentuan tingkat pemerataan dilakukan dengan menghitung Indeks Haryadi dari hubungan antara distribusi kecepatan layanan internet yang diukur dengan distribusi rujukan. Dalam hal ini, Indeks pemerataan samadengan satu adalah mewakili kesamaan yang sempurna antara elemen - elemen dari distribusi yang diukur dengan pasangan elemen - elemen dari distribusi rujukan. Misalkan $R$ adalah distribusi rujukan = \{0,7 Mbps; 0,8 Mbps; 0,9 Mbps; 1 Mbps; 1,1 Mbps; 1,2 Mbps; 1,3 Mbps; 1,4 Mbps\} dan Y adalah distribusi internet rate yang diukur = \{1,05 Mbps; 1,2 Mbps; 1,35 Mbps; 2 Mbps; 1,65 Mbps; 1,8 Mbps; 1,95 Mbps; 2,1 Mbps\}, maka Y memiliki indeks pemerataan layanan internet sama dengan satu satu, melalui fungsi hubungan $Y=1,5 R$ karena semua elemen dari $Y$ adalah sama dengan 1,5 kali dari elemen pasangan dari $R$.
\end{abstract}

\section{Kalkulator Internet}

Untuk mempermudah perhitungan, telah dibuatkan suatu "kalkulator internet", yaitu suatu website yang menyediakan kolom isian, dimana kita dapat mengisikan informasi atau data tentang kecepatan layanan di beberapa kota atau propinsi yang akan diukur tingkat pemerataannya.

Prosedur: (1) Isilah jumlah kota atau jumlah propinsi di suatu negara yang akan diukur pemerataan layanan internetnya; (2)Isikan informasi atau data tentang kecepatan internet di setiap kota atau propinsi dan isikan distribusi rujukan; (3) tekan CALCULATE

Alamat website tersebut adalah pada link "Calculation the Equity Level of an Internet Service" yang ada homepage saya di http://sigitharyadi.net/ 


\section{Penjelasan cara perhitungan}

I. Menghitung share dari kecepatan internet di kota-kota atau propinsi-propinsi yang diukur, yaitu dengan menggunakan rumus: $\mathrm{Si}=($ kecepatan internet di suatu kota atau suatu propinsi dibagi dengan total dari kecepatan internet).

II. Lalu dihitung indeks pemerataan dari layanan internet, dengan menggunakan rumus " Indeks Haryadi” berikut ini:

$$
H I=\frac{1}{\left[N^{*}\left\{\sum_{i=1}^{N} S_{i}^{2}+\sum_{i=1}^{N} \sum_{j=1}^{N}\left(S_{i}-S_{j}\right)^{2}\right\}\right]} ; i>j
$$

III. Lalu ditentukan tingkat kompetisi sebagai berikut:

a) Indeks Haryadi antara 0,90 sampai dengan 1,00 adalah bersesuaian dengan Tingkat pemerataan layanan internet yang sangat baik.

b) Indeks Haryadi antara 0,75 sampai dengan 0,89 adalah bersesuaian dengan Tingkat pemerataan layanan internet yang baik.

c) Indeks Haryadi antara 0,60 sampai dengan 0,74 bersesuaian dengan Tingkat pemerataan layanan internet yang hampir buruk.

d) Indeks Haryadi antara 0,50 sampai dengan 0,59 bersesuaian dengan Tingkat pemerataan layanan internet yang buruk.

e) Indeks Haryadi kurang dari 0,50 adalah bersesuaian dengan Tingkat pemerataan layanan internet yang sangat buruk.

\section{Catatan}

Agar dapat memahami konsep "Indeks Haryadi" yang menjadi roh dari kalkulator ini, dipersilakan membaca tulisan - tulisan saya di daftar pustaka berikut ini

\section{References}

[1] Dyah Rakhma Ariyanti; Sigit Haryadi. (October 2017). Analysis of Harmony In Gradation Index on 5G Cellular Network Quantitative Analysis. The 11th International Conference on Telecommunication Systems, Services, and Applications, At Lombok, Indonesia.

[2] Haryadi, S. (2017, November). Probabilitas Statistik Untuk Insinyur. Researchgate. DOI10.13140/RG.2.2.14304.58885

[3] Haryadi, S. (2018, February 1). Indeks Haryadi dan Prospeknya Untuk Menjadi Suatu "Formula of Everything (versi 31 Desember 2017). Retrieved from osf.io/zex45

[4] Haryadi, S. (2018, February 1). KALKULATOR untuk membuat Regresi Linier Tanpa Intersep. Retrieved from osf.io/emvs7

[5] Haryadi, S. (2018, February 1). Kalkulator Untuk Mengukur Tingkat Kompetisi di suatu Industri, dengan menggunakan rumus Indeks Haryadi. Retrieved from osf.io/fy $7 \mathrm{zu}$ 
[6] Haryadi, S. (2018, February 17). Calculation the Competition Levels between Students in Class and the Relation to the Teacher or Lecture Fairness in Teaching. Researchgate. DOI10.13140/RG.2.2.30359.06569

[7] Haryadi, S. (2018, February 17). Perhitungan Tingkat Kompetisi antar Murid atau Mahasiswa di Kelas dan Kaitannya Dengan Keadilan Guru atau Dosen Dalam Mengajar. Retrieved from osf.io/a894w

[8] Haryadi, S. (2018, February 22). Equality Correlation Calculation. Researchgate. DOI10.13140/RG.2.2.22068.76168

[9] Haryadi, S. (2018, February 22). Kalkulator Untuk Menghitung Korelasi Kesetaraan. Retrieved from osf.io/preprints/inarxiv/7r9jy

[10] Haryadi, S. (2018, February 24). Calculation of "Channel Cavity" on Data Communications. Equality Correlation Calculation. Research gate.

DOI10.13140/RG.2.2.30536.01288

[11] Haryadi, S. (2018, February 24). Perhitungan "Rongga Kanal" pada Komunikasi Data. Retrieved from osf.io/preprints/inarxiv/y3wcg

[12] Haryadi, S. (2018, February 28). Ikhtisar Organisasi Regulasi Telekomunikasi. Retrieved from osf.io/preprints/inarxiv/g9m3k

[13] Haryadi, S. (2018, February 7). Statistik Terapan: Pengujian Regulasi \& Kebijakan Telekomunikasi. Retrieved from osf.io/3pkfw

[14] Haryadi, S. (2018, January 25). Chapter 1. The Concept of Telecommunication Network Performance and Quality of Service. Retrieved from osf.io/mukqb

[15] Haryadi, S. (2018, January 26). Chapter 2 of Network Performance and Quality of Service: Determination of Key Performance Indicator (KPI). Retrieved from osf.io/preprints/inarxiv/6gtnd

[16] Haryadi, S. (2018, January 26). Chapter 3 of Network Performance and Quality of Service: Technical Measurement of a Mobile Network Performance and Quality of Service. Retrieved from osf.io/q4wsz

[17] Haryadi, S. (2018, January 30). Basic Calculation of the Network's Availability and Reliability (Chapter 4 of Network Performance and Quality of Service). Retrieved from osf.io/preprints/inarxiv/z5mwq

[18] Haryadi, S. (2018, March 1). Kebijakan Lisensi Telekomunikasi. Retrieved from osf.io/7 wbjf

[19] Haryadi, S. (2018, March 5). Performance Measurement of Internet Service. Retrieved from osf.io/9nsw3

[20] Haryadi, S., \& Riani, W. (2018, March 5). METODE PENETAPAN TARIF PAJAK PENGHASILAN YANG BERKEADILAN. Retrieved from osf.io/preprints/inarxiv/ayg58

[21] Nie Levin Kusuma Adiatma ; Sigit Haryadi. (2017, October). Comparison of the Haryadi Index with Existing Method in Competition, Equality, Fairness, and Correlation Level Calculation Case Study: Telecommunication Industry. The 11th International Conference on Telecommunication Systems, Services, and Applications, At Lombok, Indonesia.

[22] Sigit Haryadi. (2016). Haryadi Index for Competition, Equality and Correlation Evaluation. Penerbit Lantip Safari Media, Bandung, Indonesia. ISBN978602-73231-3-2

[23] Sigit Haryadi. (2016). Haryadi Index untuk Evaluasi Kompetisi, Kesetaraan dan Korelasi. Penerbit Lantip Safari Media, Bandung, Indonesia. ISBN978-60273231-3-1 
[24] Sigit Haryadi. (2017). Calculation of the Mobile Communication Competition using Haryadi Index. DOI10.13140/RG.2.2.15634.25280

[25] Sigit Haryadi. (2017). Harmony in Gradation and its prospects as the Formula of Everything, First edition of posts: December 31, 2017. Researchgate.

DOI10.13140/RG.2.2.19309.08169

[26] Sigit Haryadi. (2017). Haryadi Index and Its Applications in Science of Law, Sociology, Economics, Statistics, and Telecommunications. Penerbit Elex Media Komputindo. Jakarta. ISBN978-602-02-9895-5.

[27] Sigit Haryadi. (2017). Indeks Haryadi dan Penerapan di Ilmu Hukum, Sosiologi, Ekonomi, Statistik, dan Telekomunikasi. Penerbit Elex Media Komputindo, Jakarta. ISBN978-602-02-9896-2

[28] Sigit Haryadi. (2017). the Equality Correlation Method. Researchgate. DOI10.13140/RG.2.2.10443.80169.

[29] Sigit Haryadi. (2017). the Non-Intercept Linear Regression Method. Researchgate. DOI10.13140/RG.2.2.18721.71522

[30] Sigit Haryadi. (2017). The. Fairness over Inequality Index: Unfairness is Disaster - a notebook of Sigit Haryadi. Researchgate.

DOI10.13140/RG.2.2.34379.49449.

[31] Sigit Haryadi. (2017, December). Calculator for Measurement the Competition Index \& Level. Researchgate. DOI10.13140/RG.2.2.23626.26568

[32] Sigit Haryadi. (2017, December). Calculator for non-intercept linear regression. Researchgate. DOI10.13140/RG.2.2.15761.94562.

[33] Sigit Haryadi. (2017, January). Calculation of the Income Equality Levels between Regions using the Haryadi Index. Researchgate.

DOI10.13140/RG.2.2.36605.77282

[34] Sigit Haryadi. (2018, February). Applied Statistics for Assessment of the Regulation and Policy: case study in Telecommunication Industry.

DOI10.13140/RG.2.2.15774.02884

[35] Sigit Haryadi; Dyah Rakhma Ariyanti. (October 2017). The Fairness of Resource Allocation and Its Impact on 5G Ultra-Dense Cellular Network Performance. The 11th International Conference on Telecommunication Systems, Services, and Applications, At Lombok, Indonesia.

[36] Westi Riani; Sigit Haryadi. (2017). CALCULATOR for the Government to make the Fair Policy of Tax Rates. Researchgate. DOI10.13140/RG.2.2.18550.50246. Available online at http://sigitharyadi.net/multidicipline/income-tax-rates-calculatorid/

[37] Westi Riani; Sigit Haryadi. (2017). The Method Of Tax Rate Determination Based On Fairness. Prosiding Seminar Nasional SNaPP2017, Bandung, Indonesia. 